\title{
Ana Isabel Guérin y Roberto Olivieri (editores) Los medios públicos: un nuevo modelo comunicacional.
}

Buenos Aires: Radio y Televisión Argentina (RTA), 2013. 224 p.

Los medios públicos, un nuevo modelo comunicacional es un libro realizado por un equipo de trabajo de Radio y Televisión Argentina, sociedad de Estado (RTA S.E.). El objetivo de la publicación es detallar lo hecho en materia de radio y televisión pública en la última década.

El director de la publicación es Tristán Bauer y la edición y coordinación general estuvo a cargo de Ana Isabel Guérin y Roberto Olivieri Pinto. El consejo editorial lo forman Néstor Cantariño, Alberto Cantero, María Lenz y Alejandro Verano. Supervisaron la tarea Diego Romanelli y Alejandro Tumminello. Completan el equipo de trabajo miembros de Radio y Televisión Argentina. También colaboraron funcionarios de otras dependencias vinculadas con la TV Pública tales como la Comisión Nacional de Comunicaciones, el Consejo Asesor de TV Digital Abierta, Canal Encuentro y Agencia Télam. Se catalogó en septiembre de 2013.

Como el libro fue comandado desde el área institucional de la TV Pública se trata de un rico compilado con información estadística de las distintas políticas que se implementan a través de los medios públicos. Se argumenta además el trabajo hecho en la última década y se considera la Ley de Medios Audiovisuales un corolario del cambio de paradigma implementado en los últimos años en esta materia.
La TV Pública atravesó una profunda transformación en su última década de historia. Desde el punto de vista técnico el cambio fue total ya que en 2003 tenían equipos comprados en 1978. En esa línea de radicalidad, se dieron las modificaciones en la modalidad de trabajo y de gestión de la emisora de televisión abierta y del resto de los medios de comunicación que integran RTA.

El libro está prologado por el actual presidente de Radio y Televisión Argentina Sociedad de Estado, el cineasta Tristán Bauer. En su presentación destaca los cambios introducidos en la gestión de la mano de la administración pública a cargo del expresidente Néstor Kirchner y la continuidad dada en la línea bajo la presidencia de su esposa, Cristina Fernández. Se trata de una clara explicación política de la situación actual del ente estatal que preside Bauer.

La obra se estructura en cuatro partes: televisión pública, radio pública, RTA S.E. y el trabajo que se hace en materia de convergencia en la web con proyección a Latinoamérica.

Bajo el título general de "Televisión pública para el siglo XXI”, el director ejecutivo de la emisora estatal presenta la política y hace un balance de lo realizado. El primer punto se denomina "El desafío de consolidar una programación de calidad"; el segundo: "La revolución tecnológica" y 
el tercero "Cada vez más cerca de la comunidad". En esta estructura ya queda clara cuál es la lógica que se presentará en toda la obra. Se hace referencia a la pantalla de la TV Pública como un espacio que en su sexta década de vida recupera una programación a la que definen como "atractiva que privilegia la diversidad cultural y el interés público y que es cada vez más reconocida por el pueblo". Además, se describen la programación de la emisora, los cambios en los distintos tipos de productos y se mencionan sus coberturas especiales.

Luego se explica la política implementada en materia de difusión del deporte argentino, que le sirvió para incrementar las mediciones de audiencia en materia de rating y fundamentar así el incremento en llegada "al pueblo" que se plantea en toda la obra. "La Televisión Pública acompañó la política de Estado de promoción del deporte. El camino se inició con la transmisión de los juegos olímpicos Beijing 2008 y en 2009 llegó Fútbol para todos, destacan en la publicación. En efecto, este giro en el apoyo de la transmisión de los partidos de fútbol resultó clave para el incremento de la audiencia que tuvo la emisora estatal de acuerdo con las mediciones que realiza IBOPE en la Argentina.

En esta gestión se hizo historia en materia de producciones cinematográficas al emitirse por primera vez desde la TV Pública los siguientes largometrajes: Belgrano, la película y Revolución: el cruce de los Andes. En esa línea de fomento se produjeron dos más, tituladas Infancia clandestina y Caídos del mapa. En materia de documentales se insiste en que la intención es continuar la promoción de producciones que aborden "la historia de manera crítica". Ciclos culturales y educativos también se promueven por la emisora y se abre un capítulo especial en materia de ficción. La apuesta en este sentido fue realizar productos de calidad en coproducciones con empresas audiovisuales privadas. Además se aprovechó la política audiovisual estatal en alianza con asociaciones civiles y universidades para promover la producción en todo el territorio argentino. Así se consiguió realizar miniseries originales a través de concursos llevados adelante por el Consejo Asesor de la Televisión Digital Abierta. Este es un ejemplo de varias actividades que se han realizado en articulación con otras áreas del Estado. Finalmente, se enumera la gran cantidad de distinciones que recibieron todas estas producciones en los últimos años.

Se dedica un capítulo aparte a los avances tecnológicos implementados en medios públicos: desde la elección de la norma digital de transmisión terrestre, la instalación de antenas y la política inclusiva que se determinó realizar en ese sentido. Es interesante destacar la recopilación de datos que han llevado adelante los editores y resulta útil para cualquier trabajo de investigación. Además, se detalla la incorporación de tecnología que tuvo el canal luego de estar detenida en su actualización tecnológica entre 1978 y 2006. Desde este último año se logró cambiar radicalmente las instalaciones y mejorar las posibilidades de producción de la emisora. En el 
último apartado se enumeran las distintas actividades llevadas a cabo para que la comunidad argentina aproveche las producciones públicas. Resulta interesante ver la variedad de opciones que tienen los distintos sectores sociales para participar del principal medio público argentino.

El acápite de Radio Pública lo presenta su directora ejecutiva, María Seoane, y los puntos sobre los que se trabaja se denominan: "La voz de la identidad nacional", "Renovación de tecnología e infraestructura" y "Radio Nacional y la comunidad". Con la misma estructura del capítulo de TV Pública, se describe lo hecho por la gestión de Radio Nacional pero se pone énfasis en el trabajo federal que se hace cotidianamente desde la emisora. Además se explica el trabajo en las FM temáticas: de Rock, de Folklore, Clásica y en el servicio por onda corta Radiodifusión Argentina al Exterior (RAE).

Un trabajo similar se hace con el área dedicada a RTA, al explicar especialmente el trabajo con las emisoras de radio y televisión públicas ubicadas en distintas localizaciones del territorio nacional. En este espacio se encuentran artículos de Alberto Cantero y Alejandro Verano, ambos miembros del directorio, y de Matías Ciampini, gerente de emisoras de Radio Nacional.

En cuarto lugar, la sección titulada “Medios Públicos 2.0" incluye capítulos que explican lo realizado por la TV Pública en la web, la transmisión en vivo por internet de la radio y una descripción de una plataforma digital llamada Voces del Sur pensada para conectar a todos los medios públicos de América Latina.

La obra resulta útil para consultar datos actualizados de la radio y la televisión públicas en Argentina. El balance es válido y se hacía necesario conocer en detalle la información sobre este aspecto del mercado audiovisual argentino. Es recomendable y esperable que esta obra dé paso a un análisis académico más profundo que permita un crecimiento sostenido de este sector de la comunicación pública en el país.

\section{Marta Alicia Villar}

Universidad Austral. Facultad de Comunicación martavillar@gmail.com

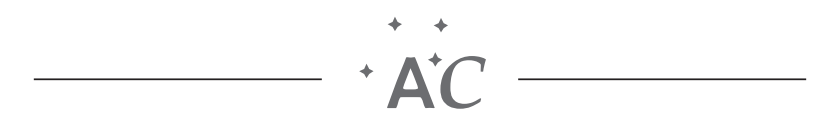

